International Journal of Engineering \& Technology, 7 (3.34)(2018) 160-162
International Journal of Engineering \& Technology
SPC
Website: www.sciencepubco.com/index.php/IJET
Research paper

\title{
Textile Industry Wastewater Color Removal Using Lemna Minor L and Lemna Minuta L
}

\author{
D. Sivakumar ${ }^{1}$, R. Anand ${ }^{2}$, Asanammal Saral ${ }^{3}$ \\ ${ }^{1,2,3}$ Department of Civil Engineering, \\ Vel Tech High Tech Dr.Rangarajan Dr.Sakunthala Engineering College, Avadi, Chennai, Tamil Nadu, India \\ *Corresponding author E-mail:shri.sivakumar1974@gmail.com
}

\begin{abstract}
The influence of various nutrient dosages, dilution ratios and $\mathrm{pH}$ values was evaluated with different contact time against colour removal from textile industry wastewater using Lemna minor $\mathrm{L}$ and Lemna minuta $\mathrm{L}$. The optimum nutrient dosage, dilution ratio, and $\mathrm{pH}$ value was found to be $50 \mathrm{mg}, 8$ and 8 respectively. The maximum colour removal corresponding to the optimum process parameters value observed using Lemna minor $\mathrm{L}$ as $82.85 \%$ and using Lemna minuta $\mathrm{L}$ as $89.5 \%$. Further, verification was done and showed that the maximum colour removal percentage from textile industry wastewater is lower than colour removal from an aqueous solution. The results of this study concluded that Lemna minuta L removed more colour than Lemna minor $\mathrm{L}$ and both were identified to reproduce the obtained optimum process parameters and for removing colour in a textile industry wastewater.
\end{abstract}

Keywords: Colour, Constructed wetland, Textile industry wastewater, Lemna minor L., Lemna minuta L.

\section{Introduction}

The textile industry wastewater comes from various wet processes like scouring, sizing, bleaching, dyeing and printing operations. The wastewater contains more organic and inorganic matter that is entering into the land and water environment when it was not treating properly. Sivakumar, Irina, and Smita $[1,2,3]$ were observed that out of all pollutant, colour in textile industry wastewater dominates because of its appearance; therefore it is to be treated before discharge on land or nearby waterbodies.

The conventional treatment approaches to eliminate colour from textile industry wastewater are aerobic and anaerobic microbial degradation and coagulation method was studied by Guendy [4], absorption studies were conducted using aquatic plants by Sivakumar and Sivakumar, et al., [5,6], granular activated carbon was used in treating the textile industry wastewater by Syafalni [7], electrochemical processes was studied by Dogan [8], reverse osmosis method was used by Ramesh Kumar [9].

Further, the ozonation method was assessed by Guendy [10], bioadsorption studies were conducted by Shankar and Sivakumar [11, 12], catalytic oxidation was used for assessing the textile industry wastewater by Hussein [13] and the application of membrane processes was studied by Abdulraheem [14] etc. The above said methods having disadvantages because of their high treatment cost. One of such cost effective treatment method is phytoremediation and it was studied by Sivakumar, Shaikh Parveen, Patel and Sivakumar $[15,16,17,18]$. Most of the studies concentrated on aqueous solution for the removal of colour, whereas, this study concentrated on removal of textile industry wastewater colour by Lemna minor $\mathrm{L}$ and Lemna minuta $\mathrm{L}$. Also verified colour removal from aqueous solution (same dye used in textile industry) using Lemna minor L and Lemna minuta L for their reproducibility.

\section{Methods and Materials}

\subsection{Lemna Minor L and Lemna Minuta L Collection}

Small duckweeds Lemna minor L and Lemna minuta L has very small leaves and short roots, has bright green in colour. Lakes, ponds are the regions where these plants are growing abundantly. These can survive in cool climate to moderately temperate climate. Lemna minor L and Lemna minuta L collected from nearby pond and both were washed with deionized water and then both were stabilized for a period of 15 days in a plastic container. The plastic container represents the constructed wetland filled with 5 inch soil collected from local lake.

\subsection{Textile Industry Wastewater Collection}

Airtight sterilized bottles were used for collection of wastewater from textile industry. The wastewater collected at clarifier from textile industry, located at Kanchipuram, Tamil Nadu. The samples were kept in refrigerator at the temperature of $278 \mathrm{~K}$ and then it was analysed for various parameter particularly colour. The colour of the wastewater is due the presence of Acid orange 10 dye, which was used by the textile industry.

\subsection{Adsorption Experiments}

$100 \mathrm{~g}$ of each Lemna minor L and Lemna minuta L collected from stabilized tank and the same was put into the constructed wetland, which was similar to stabilized tank made up of plastic. Three representative samples were maintained for analysis of colour removal using Lemna minor $\mathrm{L}$ and Lemna minuta $L$. The removal of colour was observed over 7 days period with 1 day interval. 
The selected process parameters are nutrient dosages $(10,20,30$, $40,50,60$ and $70 \mathrm{~g})$, dilution ratio $(2,4,6,8,10,12$ and 14) and $\mathrm{pH}(4,5,6,7,8,9$ and 10).

Activated sludge was used as nutrient for this study. 2, 4, 6, 8, 10, 12 and 14 represents well water with wastewater. $0.1 \mathrm{M}$ of $\mathrm{NaOH}$ and $0.1 \mathrm{M}$ of $\mathrm{HCl}$ was used to adjust the $\mathrm{pH}$ value. The wastewater colour of textile industry using Lemna minor $\mathrm{L}$ and Lemna minuta L was determined by APHA, 2005 [19]. The formula used for the adsorption removal is

Percentage Removal $=\frac{\left(C_{1}-C_{2}\right)}{C_{1}} X 100$

in which $\mathrm{C}_{1}$ and $\mathrm{C}_{2}$ are the wastewater colour of textile industry before and after treatment with Lemna minor L and Lemna minuta $\mathrm{L}$ respectively. The wastewater colour reduction in a textile industry was measured by UV spectrophotometer at $486 \mathrm{~nm}$ wavelength. The colour intensity measured as $45 \mathrm{mg} / \mathrm{l}$.

\section{Results and Discussion}

Lemna minor $\mathrm{L}$ and Lemna minuta $\mathrm{L}$ were used for removing colour from textile industry wastewater against process parameters like nutrient dosages, dilution ratios, $\mathrm{pH}$ values for different time of contact.

\subsection{Effect of Nutrient Dosage}

The nutrient dosages were changed from $10 \mathrm{~g}$ to $70 \mathrm{~g}$ with dilution ratio of 6 and $\mathrm{pH}$ of 6 for removing colour from textile industry wastewater using Lemna minor $\mathrm{L}$ and Lemna minuta $\mathrm{L}$. This study was conducted against time of contact from day 1 to day 7 and observed as day 4 showed colour removal maximum percentage from wastewater of textile industry using Lemna minor L and Lemna minuta $\mathrm{L}$ (results expect day 4 were not presented in this study).

From Fig. 1, it could be noted that maximum colour reduction from textile industry wastewater was occurred at the nutrient dosage of $50 \mathrm{~g}$ for both Lemna minor $\mathrm{L}$ and Lemna minuta $\mathrm{L}$. Beyond which there was no such variation and hence, an optimum nutrient dosage found to be $50 \mathrm{~g}$ and corresponding the maximum removal of colour at an optimum nutrient dosage of $50 \mathrm{~g}$ by Lemna minor $\mathrm{L}$ is $68.2 \%$ and by Lemna minuta $\mathrm{L}$ is $76.3 \%$ (Fig. 1).

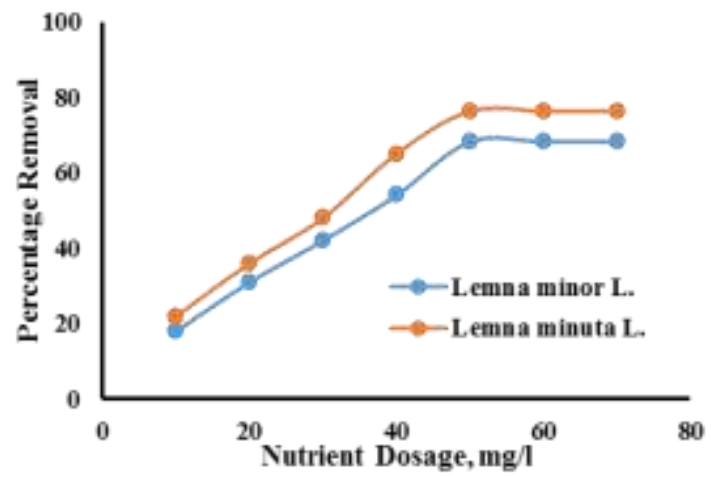

Fig. 1: Percentage Removal of Wastewater Colour from Textile Industry by Lemna minor L and Lemna minuta $\mathrm{L}$ against Nutrient Dosage

\subsection{Effect of Dilution Ratio}

The dilution ratios were changed from 2 to 14 with optimum nutrient dosage $(50 \mathrm{~g})$ and $\mathrm{pH}(6)$ for removing colour from textile industry wastewater using Lemna minor $\mathrm{L}$ and Lemna minuta $\mathrm{L}$. This study was conducted with different time of contact day 1 to day 7 and observed as day 4 showed the colour removal maximum percentage from textile industry wastewater using Lemna minor $\mathrm{L}$ and Lemna minuta $\mathrm{L}$.

From Fig. 2, it could be distinguished that maximum colour reduction from wastewater occurred at dilution ratio of 8 for both Lemna minor $\mathrm{L}$ and Lemna minuta $\mathrm{L}$. Beyond which there was no such variation and hence, an optimum dilution ratio found to be 8 and corresponding the maximum removal of colour at an optimum dilution ratio 8 by Lemna minor $\mathrm{L}$ is $76.8 \%$ and by Lemna minuta $\mathrm{L}$ is $83.4 \%$ (Fig. 2 ).

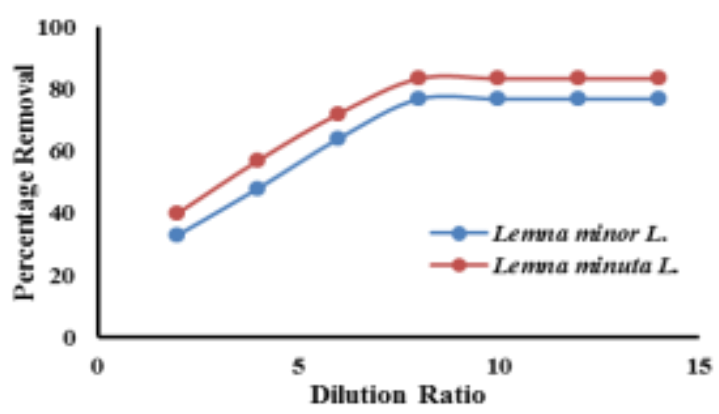

Fig. 2: Percentage Removal of Wastewater Colour from Textile Industry by Lemna minor $\mathrm{L}$ and Lemna minuta $\mathrm{L}$ against Dilution Ratio

\subsection{Effect of $\mathbf{P h}$}

The $\mathrm{pH}$ values were changed from 4 to 10 with the optimum nutrient dosage $(50 \mathrm{~g})$ and optimum dilution ratio (8) for removing colour from textile industry wastewater using Lemna minor $\mathrm{L}$ and Lemna minuta L. This study was conducted against time of contact day 1 to day 7 and observed as day 4 showed colour removal maximum percentage from textile industry wastewater using Lemna minor $\mathrm{L}$ and Lemna minuta $\mathrm{L}$.

From Fig. 3, it could be distinguished that maximum colour reduction from textile industry wastewater was occurred at $\mathrm{pH}$ of 8 for both Lemna minor L and Lemna minuta L. Beyond which there was no such variation and hence, an optimum $\mathrm{pH}$ values found to be 8 and corresponding the maximum removal of colour at an optimum pH by Lemna minor L. is $82.85 \%$ and by Lemna minuta L. is $89.5 \%$ (Fig. 3).

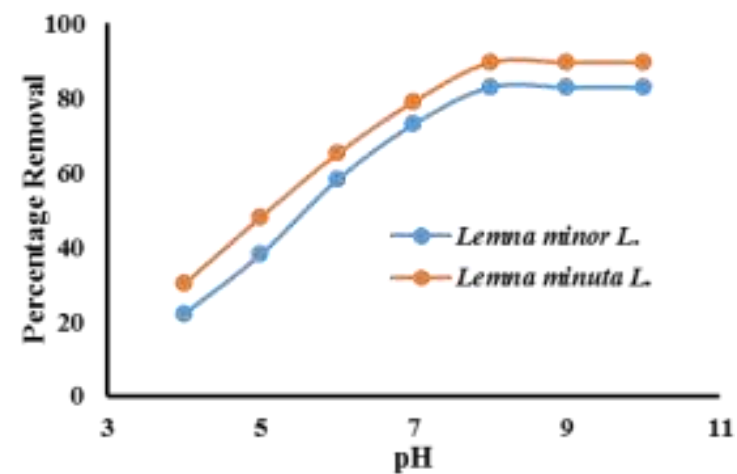

Fig. 3: Percentage Removal of Wastewater Colour from Textile Industry by Lemna minor $\mathrm{L}$ and Lemna minuta $\mathrm{L}$ against $\mathrm{pH}$

\subsection{Verification Experiment}

An experiment was conducted in an aqueous solution for removing colour using Lemna minor L and Lemna minuta L (Fig. 4) with the process parameters like optimum nutrient dosage of $50 \mathrm{~g}$, dilution ratio of $8, \mathrm{pH}$ of 8 with contact time of 4 days. An initial concentration of Acid Orange 10 colour aqueous solution was prepared with equivalent concentration of textile industry wastewater and it was measured as similar to colour determined in a textile industry wastewater with the UV spectrophotometer $\left(\lambda_{\max }=486 \mathrm{~nm}\right)$. 
The maximum removal percentage of Acid Orange 10 colour in an aqueous solution is found to be $86.35 \%$ and $92.1 \%$ respectively by Lemna minor L and Lemna minuta $\mathrm{L}$. Further, Lemna minuta L produced higher removal percentage than Lemna minor L. No other competitive parameters present in an aqueous solution and the same are influencing maximum colour removal rate in an aqueous solution. Based on verification test results, it could be established that the Lemna minor L. and Lemna minuta L. could be used to remove not only the colour along with associated parameters from textile industry wastewater against the optimum process parameters values.

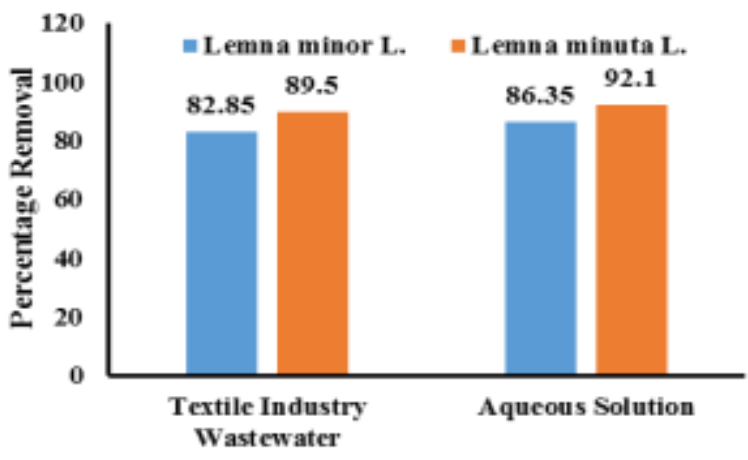

Type of Solution

Fig. 4: Wastewater Colour removal Maximum Percentage from Textile Industry and from Aqueous Solutions by Lemna minor L. and Lemna minuta $\mathrm{L}$. against optimum process parameters values.

\section{Conclusions}

Lemna minor $\mathrm{L}$ and Lemna minuta $\mathrm{L}$ aquatic plants were used for this study to remove textile industry wastewater colour against the process parameters nutrient dosages, dilution ratios and $\mathrm{pH}$ values with different contact time. Maximum removal of textile industry wastewater colour at an optimum nutrient dosage of $50 \mathrm{~g}$, dilution ratio of 8 and $\mathrm{pH}$ of 8 with contact time of 4 days was found to be $82.85 \%$ and $89.5 \%$ by Lemna minor $\mathrm{L}$ and Lemna minuta $\mathrm{L}$ respectively. The same results were observed in aqueous solution. Thus, the study was concluded that Lemna minor L. and Lemna minuta L. may be used as potential candidate for removing colour along with other associated parameters from textile industry wastewater.

\section{Acknowledgement}

The Authors express their thanks to Management of Vel Tech High Tech Dr.Rangarajan Dr.Sakunthala Engineering College, Avadi, Chennai, Tamil Nadu, India, for their provisions to finish this study successfully.

\section{References}

[1] Sivakumar, D., and Shankar, D., 2012. Effect of aeration on colour removal from textile industry wastewater, International Journal of Environmental Sciences, 2(3), 1386-1397.

[2] Irina, I.S., and Romen, B., 2008. Wastewater characteristics in textile finishing Mills, Environmental Engineering and Management Journal, 7(6), 859-864.

[3] Smita, V., Pandey, N.D., Quoff, A.R., 2014. Decolorization of Synthetic Dye Solution Containing Congo Red By Advanced Oxidation Process (AOP), International Journal of Advanced Research in Civil, Structural, Environmental and Infrastructure Engineering and Developing, 2(1), 49-55.

[4] Guendy, H.R., 2010. Treatment and reuse of wastewater in the textile industry by means of coagulation and adsorption techniques, Journal of App. Sci. Res., 6(8), 964-972.
[5] Sivakumar, D., 2014. Role of Lemna minor lin. In treating the textile industry wastewater, International Journal of Environmental, Earth Science and Engineering 8(3), 55-59.

[6] Sivakumar, D., Shankar, D., Dhivya, P., and Balasubramanian, K., 2014. Bioaccumulation study by Lemna Gibba lin, Pollution Research, 33(3), 531-536.

[7] Syafalni S., Ismail, A., Irvan, D., Chan, K.W., and Genius, U., 2012 Treatment of dye wastewater using granular activated carbon and zeolite filter, Modern Applied Science, 6(2), 37-51.

[8] Dogan, D., and Haluk, T., 2012. Electrochemical Treatment of Actual Textile Indigo Dye Effluent, Pol. J. Environ. Stud., 5, 1185 1190.

[9] Ramesh Kumar, M., Koushik, C.V., and Saravanan, K., 2013. Textile wastewater treatment using reverse osmosis and SDI, Elixir Chem. Engg., 54A, 12713-12717.

[10] Guendy, H.R., 2007. Ozone treatment of textile wastewater relevan to toxic effect elimination in marine environment, Egyptian Journal of Aquatic Research, 33(1), 98-115.

[11] Shankar, D., Sivakumar, D., Thiruvengadam, M., and Manojkumar, M., 2014. Colour removal in a textile industry wastewater using coconut coir pith, Pollution Research, 33(3), 449-503.

[12] Sivakumar Durairaj, and Shankar Durairaj, 2012. Colour removal from textile industry wastewater using low cost adsorbents, International Journal of Chemical, Environmental and Pharmaceutical Research, 3(1), 52-57.

[13] Hussein, F.H., and Abass, T.A., 2010. Photocatalytic treatment of textile industrial wastewater. Int. J. Chem. Sci., 8(3), 1353-1364

[14] Abdulraheem, G. and Abiodun, O., 2012. The Applications of membrane operations in the textile industry: A review. British Journal of Applied Science \& Technology, 2(3), 296-310.

[15] Sivakumar, D., Kandaswamy, A.N., Arivoli, E., and Sesha Sayee, V., 2014. Application of lemna minor lin. on reduction of contaminants in a textile industry effluent. International Journal of Civil Engineering and Technology, 5(3), 285-293.

[16] Shaikh Parveen, R., and Bhosle Arjun, B., 2011. Bioaccumulation of chromium by aquatic macrophytes hydrilla sp. \& chara sp., Advances in Applied Science Research, 2(1), 214-220.

[17] Patel, D., and Kanungo, V., 2010. Phytoremidation potential of duckweed (lemna minor 1: a tiny aquatic plant) in the removal of pollutants from domestic wastewater with special reference to nutrients, The Bio sci., 5(3), 355-358.

[18] Sivakumar, D., Shankar, D., Vijaya Prathima, A.J.R, and Valarmathi, M., 2013. Constructed wetlands treatment of textile industry wastewater using aquatic macrophytes, International Journal of Environmental Science, 3(4), 1223-1232.

[19] APPA, AWWA, and WEF, 2005. Standard methods for the examination of water and wastewater, $21^{\text {st }}$ edition, APHA Publication, Washington D.C. 